\title{
Karakteristik, Pengetahuan Gizi Ibu dan Status Gizi Balita (BB/TB) Usia 6-59 bulan
}

\section{Maternal Characteristics, Nutritional Knowledge and Nutritional Status (WHZ) among 6-59 Months Old Toddlers}

\author{
Aisyah Nanda Amirah*1, Mahmud Aditya Rifqi ${ }^{2}$
}

\begin{abstract}
ABSTRAK
Latar Belakang: Wasting adalah salah satu permasalahan gizi yang terjadi pada balita. Wasting dapat mengakibatkan terhambatnya pertumbuhan balita serta mempengaruhi produktivitasnya kelak. Ibu berperan besar dalam mempengaruhi pemenuhan kebutuhan asupan anak. Karakteristik serta pengetahuan gizi ibu mempunyai peranan dalam mencapai status gizi yang sesuai untuk anak.

Tujuan: Menganalis hubungan karakteristik ibu (pendidikan dan pekerjaan) dan pengetahuan gizi ibu dengan status gizi (BB/TB) dari balita usia 6-59 bulan

Metode: Jenis penelitian ini merupakan penelitian observasional dengan rancangan desain cross-sectional. Penelitian dilselenggarakan pada bulan Oktober 2018 di wilayah kerja dari Puskesmas Kesamben Ngoro Kabupaten Jombang, Jawa Timur. Sampel penelitian yaitu 91 balita usia 6-59 bulan. Pemilihan sampel dilakukan dengan teknik random sampling. Variabel independen adalah karakteristik ibu (pendidikan dan pekerjaan) dan pengetahuan gizi ibu. Variabel dependen yang diteliti adalah status gizi balita dengan indeks antropometri berat badan menurut tinggi badan (BB/TB). Uji statistik yang digunakan yaitu chi square dan uji spearman.

Hasil: Hasil penelitian menunjukkan adanya hubungan yang signifikan antara pekerjaan ibu dan status gizi anak usia 6-59 bulan $(p=0,001)$ sedangkan pendidikan ibu $(p=0,080)$ dan pengetahuan gizi ibu $(p=0,593)$ tidak berhubungan

Kesimpulan: Status gizi balita (BB/TB) berhubungan terhadap pekerjaan ibu. Ibu yang tidak bekerja dapat meluangkan lebih banyak waktunya untuk mengontrol asupan makanan anak dan dapat berdampak pada status gizi anak yang optimal.

Kata kunci: karakteristik, ibu, wasting, balita
\end{abstract}

\section{ABSTRACT}

Background: Wasting is one of the nutritional problems that occur in toddlers. Wasting can inhibit the toddler's growth and effected to their productivity in the future. Mothers have a significant role to affect the nutritional status of their child. The characteristics and nutrition knowledge of mother have a necessary influence in optimizing the nutritional status of the child.

Objective: This study aimed to analyze the association of maternal characteristics and nutrition knowledge with nutritional status (WHZ) among 6-59 months of toddler

Methods: This study was an observational study with a cross-sectional study design. The study was conducted in October 2018 in Kesamben Village, Ngoro Sub District, Jombang. The research sample was 91 toddlers aged 6-59 months. The sample selection was done by random sampling technique. The independent variables were maternal characteristics (employement status and education) and nutrition knowledge of mother. The dependent variable was the nutritional status of toddler with anthropometric index weight for height (WHZ). The statistical test used were chi square and spearman test. Results: The results of the study showed a significant relationship between maternal employment and nutritional status (WHZ) of children aged 6-59 months $(p=0.001)$ while maternal education $(p=0.080)$ and mother's nutrition knowledge $(p=$ 0.593) were not related

Conclusion: Nutritional status of toddler is influenced by maternal employment. Unemployed mother can spend more time to control the diary intake of their child and improve their optimal nutritional status.

Keywords: characteristics, mother, wasting, toddler

*Koresponden :

aisyahnanda99@gmail.com

1,2Departemen Gizi Kesehatan, Fakultas Kesehatan Masyarakat, Universitas Airlangga, Kampus C Mulyorejo 66115, Surabaya, Jawa Timur, Indonesia 


\section{PENDAHULUAN}

Gizi merupakan faktor yang berperan besar dalam tercapainya tumbuh kembang optimal bagi balita. Terpenuhinya kebutuhan gizi menjadi hal yang diprioritaskan oleh orangtua karena fase ini bersifat irreversible atau permanen ${ }^{1}$. Di Indonesia, salah satu masalah yang berkaitan dengan gizi pada anak balita yaitu wasting. Berdasarkan Riset Kesehatan Dasar (Riskesdas) tahun 2018, prevalensi wasting di Indonesia sebesar $10,2 \%^{2}$.

Wasting adalah suatu keadaan kekurangan gizi akut pada balita. Berat badan menurut tinggi badan (BB/TB) merupakan indeks antropometri yang mengindikasikan terjadinya wasting. Indikator ini menggambarkan akutnya masalah gizi akibat dari keadaan yang berlangsung dalam waktu singkat ${ }^{3}$. Wasting secara langsung disebabkan karena asupan gizi inadekuat dan penyakit infeksi pada anak sedangkan secara tidak langsung dapat dipengaruhi oleh faktor sosial ekonomi, pola asuh, ketersedian pangan serta faktor budaya ${ }^{4}$. Wasting dapat berdampak pada penurunan daya eksplorasi anak. Pada jangka panjang, anak yang mengalami wasting juga dapat berpengaruh terhadap penurunan kecerdasan, produktifitas serta kualitas Sumber Daya Manusia ${ }^{5}$.

Masa balita menjadi masa yang rentan dikarenakan tingginya kebutuhan zat gizi untuk menunjang proses tumbuh kembang serta sistem imunnya yang masih dalam proses pematangan ${ }^{6,7}$. Ibu mempunyai pengaruh yang besar untuk dapat menjaga masa balita anak agar tumbuh dan kembangnya dapat optimal ${ }^{8}$. Ibu berperan dalam menjaga dan mengawasi asupan makan anak. Pemenuhan asupan makan yang mencukupi kebutuhan dapat memberikan dampak terhadap status gizi. Peranan ibu dalam pemberian makan anak dapat dipengaruhi dari karakteristik ibu dan pengetahuan gizi ibu. Berdasarkan penelitian terdahulu terdapat hubungan antara pendidikan ibu dan pekerjaan ibu terhadap status gizi pada balita di wilayah kerja dari Puskesmas Nanggalo, Padang ${ }^{9}$. Selain itu, secara tidak langsung pengetahuan gizi ibu dapat berpengaruh pada status gizi anak. Penelitian yang dilakukan pada balita di wilayah kerja dari Puskesmas Sidotopo, Surabaya, menunjukkan bahwa adanya hubungan antara pengetahuan ibu terkait gizi dengan status gizi anak balita ${ }^{10}$. Semakin baik pengetahuan ibu terkait gizi yang dimiliki, maka ibu akan dapat memberikan perlakuan yang tepat untuk mengoptimalkan gizi anak agar terjaga dengan baik.

Masalah wasting atau kurus di Jawa Timur telah mengalami penurunan. Berdasarkan data Riskesdas (2018), diketahui angka prevalensi balita dengan status gizi kurus dan sangat kurus di Jawa Timur sebesar 9,2\% ${ }^{2}$. Angka ini telah mengalami penurunan dibanding dari tahun 2013 yaitu sebesar 11,4\%. Walaupun telah mengalami penurunan, tetapi angka ini masih dianggap menjadi masalah kesehatan masyarakat karena prevalensi kekurusan $>5 \%{ }^{11}$.

Tujuan penelitian ini yaitu menganalisis hubungan karakteristik (pendidikan dan pekerjaan) dan pengetahuan gizi ibu dengan status gizi balita usia 6-59 bulan di wilayah kerja dari Puskesmas Kesamben Ngoro, Kabupaten Jombang.

\section{METODE}

Jenis penelitian yang digunakan dalam penelitian ini yaitu penelitian observasional dengan rancangan desain cross-sectional. Penelitian dilaksanakan pada bulan Oktober 2018 di wilayah kerja dari Puskesmas Kesamben Ngoro, Kabupaten Jombang, Jawa Timur. Populasi pada penelitian ini merupakan seluruh balita yang tinggal dan terdaftar di wilayah dari kerja Puskesmas Kesamben Ngoro Kabupaten Jombang yaitu sebanyak 1887 balita. Berdasarkan rumus slovin, maka didapatkan jumlah sampel dari penelitian ini sebesar 91 balita. Sampel penelitian kemudian dipilih dengan teknik simple random sampling. Pemilihan sampel secara acak didasarkan nama balita yang terdapata di wilayah kerja dari Puskesmas Kesamben Ngoro pada bulan September-Oktober 2018.

Pada penelitian ini variabel independen yang digunakan yaitu karakteristik ibu (pendidikan dan pekerjaan) dan pengetahuan gizi ibu. Pendidikan ibu merupakan pendidikan terakhir yang telah ibu tempuh. Klasifikasi variabel pendidikan ibu terbagi tidak tamat SD, tamat SD, tamat SMP, tamat SMA, dan perguruan tinggi. Pekerjaan ibu adalah pekerjaan yang dilakukan ibu yang menghasilkan penghasilan bagi keluarga. Pekerjaan ibu terbagi menjadi bekerja dan tidak bekerja. Pengetahuan ibu terkait gizi diperoleh dari hasil kuesioner yang berisi 20 soal $^{12}$. Pertanyaan mengenai pengetahuan gizi berisi seputar contoh dan manfaat zat gizi, status gizi anak dan pola makan anak. Klasifikasi variabel pengetahuan gizi ibu terbagi menjadi pengetahuan gizi yang kurang ( $<60 \%$ jawaban benar), cukup (60-80\% jawaban benar), dan baik (> $80 \%$ jawaban benar).

Variabel dependen yaitu status gizi balita menggunakan indeks berat badan menurut tinggi badan (BB/TB). Pengambilan data untuk data antropometri berat badan dan tinggi badan balita didapatkan secara langsung dari hasil penimbangan pada kegiatan bulanan di posyandu. Hasil dari pengukuran kemudian di entry ke software WHO Anthro untuk mendapatkan nilai Z-Score. Nilai Z-Score antropometri pada indeks BB/TB yaitu status gizi kurus/sangat kurus $(<-2 \mathrm{SD})$, dan status gizi normal/gemuk ( $\leq-2 \mathrm{SD})$. Data mengenai karakteristik (pekerjaan ibu dan pendidikan ibu) dan pengetahuan gizi ibu yang diperoleh secara langsung dari hasil wawancara kuesioner kepada ibu balita. Data diolah dan dianalisis dengan aplikasi IBM SPSS Statistics 24 menggunakan uji spearman dan chi square.

\section{HASIL DAN PEMBAHASAN}

Berdasarkan tabel 1, responden ibu balita sebagian besar tidak bekerja yaitu sebesar $83,5 \%$ sedangkan ibu yang bekerja jika dihitung keseluruhan sebanyak $16,5 \%$. Sebagian besar responden ibu balita berpendidikan terakhir terbanyak yaitu SMA sebesar $53,8 \%$. Sebagian besar responden mempunyai pengetahuan gizi sedang (60-80\%) yaitu sebesar $64,8 \%$. 
Tabel 1. Distribusi Karakteristik (Pekerjaan Ibu dan Pendidikan Ibu) dan Pengetahuan Gizi Ibu

\begin{tabular}{|c|c|c|}
\hline Variabel & Jumlah $(n)=91$ & Persentase (\%) \\
\hline \multicolumn{3}{|l|}{ Pekerjaan Ibu } \\
\hline Tidak bekerja & 76 & 83,5 \\
\hline Bekerja & 15 & 16,5 \\
\hline \multicolumn{3}{|l|}{ Pendidikan Ibu } \\
\hline Tidak Tamat SD & 1 & 1,1 \\
\hline Tamat SD & 5 & 5,5 \\
\hline Tamat SMP & 29 & 31,9 \\
\hline Tamat SMA & 49 & 53,8 \\
\hline Perguruan Tinggi & 7 & 7,7 \\
\hline \multicolumn{3}{|l|}{ Pengetahuan Gizi Ibu } \\
\hline Kurang $(<60 \%)$ & 12 & 13,2 \\
\hline Sedang $(60 \%-80 \%)$ & 59 & 64,8 \\
\hline Baik (> 80\%) & 20 & 22,0 \\
\hline
\end{tabular}

Tabel 2. Distribusi Status Gizi Balita Berdasarkan Indeks Antropometri BB/TB

\begin{tabular}{llll}
\multicolumn{1}{c}{ Kategori Status Gizi } & Jumlah $(\mathbf{n})=\mathbf{9 1}$ & \multicolumn{1}{c}{ Persentase (\%) } \\
\hline Kurus/sangat kurus(<-2SD) & 4 & 4,4 & \\
Normal/gemuk $(\geq-2$ SD) & 87 & 95,6 & \\
\hline
\end{tabular}

Tabel 3. Hubungan Pendidikan, Pekerjaan dan Pengetahuan Gizi Ibu dengan Status Gizi Balita

\begin{tabular}{|c|c|c|c|c|c|c|c|}
\hline \multirow{3}{*}{ Variabel } & \multicolumn{4}{|c|}{ Status Gizi BB/TB } & \multirow{2}{*}{\multicolumn{2}{|c|}{ Jumlah $(n)=91$}} & \multirow{3}{*}{$p$ Value } \\
\hline & \multicolumn{2}{|c|}{$\begin{array}{c}\text { Gizi Kurus/ } \\
\text { Sangat kurus }\end{array}$} & \multicolumn{2}{|c|}{$\begin{array}{c}\text { Gizi } \\
\text { Normal/Gemuk }\end{array}$} & & & \\
\hline & $\mathbf{n}$ & $\%$ & $n$ & $\%$ & $\mathbf{N}$ & $\%$ & \\
\hline \multicolumn{8}{|l|}{ Pendidikan Ibu } \\
\hline Tidak Tamat SD & 0 & 0 & 1 & 1,1 & 1 & 1,1 & \multirow{5}{*}{0,080} \\
\hline Tamat SD & 0 & 0 & 5 & 5,5 & 5 & 5,5 & \\
\hline Tamat SMP & 0 & 0 & 29 & 31,9 & 29 & 31,9 & \\
\hline Tamat SMA & 3 & 3,3 & 46 & 50,5 & 49 & 53,9 & \\
\hline Perguruan Tinggi & 1 & 1,1 & 6 & 6,6 & 7 & 7,7 & \\
\hline \multicolumn{8}{|l|}{ Pekerjaan Ibu } \\
\hline Tidak bekerja & 1 & 1,1 & 75 & 82,4 & 76 & 83,5 & \multirow[t]{2}{*}{0,001} \\
\hline Bekerja & 3 & 3,3 & 12 & 13,2 & 15 & 16,5 & \\
\hline \multicolumn{8}{|c|}{ Pengetahuan Gizi lbu } \\
\hline Kurang baik & 0 & 0 & 12 & 13,2 & 12 & 13,2 & \multirow{3}{*}{0,593} \\
\hline Sedang & 3 & 3,3 & 56 & 61,5 & 59 & 64,8 & \\
\hline Baik & 1 & 1,1 & 19 & 20,9 & 20 & 22,0 & \\
\hline
\end{tabular}

Ibu dengan pengetahuan gizi kurang $(<60 \%)$ sebesar $13,2 \%$ dan dengan pengetahuan gizi baik $(>80 \%)$ yaitu $22 \%$. Penelitian ini menggunakan indeks antropometri yaitu berat badan menurut tinggi badan (BB/TB. Indeks berat badan menurut tinggi badan (BB/TB) dapat memberikan gambaran status gizi balita saat ini sehingga cukup sensitif dalam melihat perubahan jangka pendek atau singkat dari status gizi. Berdasarkan tabel 3, diketahui bahwa balita pada usia 659 bulan di wilayah kerja dari Puskesmas Kesamben Ngoro yang termasuk dalam kategori status gizi kurus/ sangat kurus sebesar 4,4\% sedangkan 95,6\% memiliki status normal/gemuk. Anak menjadi kurus atau wasting dapat disebabkan wabah penyakit ataupun anak kekurangan makan.

Berdasarkan tabel 3, didapatkan hasil bahwa tidak terdapat hubungan antara pendidikan ibu dan pengetahuan gizi dari ibu terhadap status gizi anak balita usia 6-59 bulan di wilayah kerja Puskesmas Kesamben Ngoro. Ibu dengan pendidikan dan pengetahuan gizi yang baik belum tentu memiliki anak dengan status gizi normal.
Walaupun demikian, berdasarkan penelitian ini ditemukan hubungan signifkan antara pekerjaan ibu terhadap status gizi balita.

Pendidikan ibu adalah pendidikan dengan jenjang formal terakhir yang ibu tempuh. Pendidikan ibu yang tinggi dapat meningkatkan kemampuannya dalam menerima informasi, meningkatkan keterampilan serta memberikan pengasuhan yang positif pada anak. Hasil analisis menggunakan uji spearman menunjukkan bahwa tidak ditemukan hubungan yang signifikan antara pendidikan ibu dengan status gizi balita dengan nilai $p=$ $0,080(p>0,050)$. Hal ini dikarenakan balita dengan status gizi kurus dan sangat kurus terdapat pada ibu dengan pendidikan tamat SMA dan perguruan tinggi sebesar $3,3 \%$ dan $1,1 \%$ sedangkan pada jenjang dibawahnya tidak ada. Hasil penelitian ini sesuai dengan penelitian sebelumnya yang membuktikan tidak adanya hubungan antara tingkat pendidikan ibu dengan kejadian wasting $^{13}$. Ibu dengan pendidikan yang tinggi belum tentu mempunyai anak dengan status gizi normal. 
Seorang anak dengan ibu berpendidikan tinggi akan berisiko lebih rendah mengalami malnutrisi ${ }^{14}$. Walaupun pada penelitian ini, tidak ditemukan adanya hubungan antara pendidikan ibu dengan status gizi anak tetapi telah banyak penelitian yang menunjukkan hubungan yang signifikan. Penelitian lain menyebutkan bahwa adanya hubungan antara pendidikan orangtua dengan status gizi anak usia 12-36 bulan di Taman, Sidoarjo ${ }^{15}$.

Secara tidak langsung pekerjaan ibu mempunyai hubungan terhadap status gizi pada anak. Hasil dari analisa menggunakan uji chi-square pada tabel 3 menunjukkan adanya hubungan yang signifikan antara pekerjaan ibu dengan status gizi balita yaitu dengan nilai $p=0,001(p<0,050)$. Ibu yang tidak bekerja $82,4 \%$ mempunyai anak dengan status gizi normal/gemuk dan $1,1 \%$ status gizi kurus/sangat kurus. Ibu yang bekerja mempunyai anak dengan status gizi normal/gemuk $13,2 \%$ dan 3,3\% dengan status gizi kurus/sangat kurus.

Berdasarkan penelitian ini, ibu bekerja lebih banyak mempunyai anak dengan status gizi kurus/sangat kurus daripada tidak bekerja. Hasil tersebut selaras dengan penelitian sebelumnya yang menunjukkan bahwa terdapat hubungan antara pekerjaan ibu dengan status gizi balita ${ }^{16,17}$. Ibu bekerja memiliki waktu lebih terbatas dan sedikit untuk memberikan perhatian pada anaknya dibanding ibu tidak bekerja. Ibu tidak bekerja dapat mempunyai waktu yang lebih banyak untuk mengasuh balita sehingga dapat mempengaruhi status gizi dengan pemberian makanan yang sesuai dengan kebutuhan anaknya ${ }^{18}$. Ibu akan lebih sering terlibat langsung dalam mengawasi asupan makan anak-anak. Walaupun demikian, penelitian lain menunjukkan tidak adanya hubungan pekerjaan ibu dengan status gizi dari balita usia 12-24 bulan pada wilayah kerja dari Puskesmas Tambak Wedi, Surabaya ${ }^{19}$. Tetapi hasil tersebut tidak sesuai dengan sampel dari penelitian ini.

Pengetahuan terkait gizi penting diperlukan ibu untuk dapat mengoptimalkan status gizi anak. Tanpa adanya pengetahuan mengenai gizi, ibu tidak dapat memberikan pengasuhan yang tepat dan anak dapat berisiko mengalami masalah gizi. Berdasarkan tabel 3, hasil dari analisis menggunakan uji spearman menunjukkan bahwa tidak ditemukan adanya hubungan signifikan antara pengetahuan gizi dari ibu dengan status gizi balita yaitu nilai $p=0,593(p>0,050)$. Anak dengan status gizi kurus/sangat kurus hanya terdapat pada ibu dengan pengetahuan gizi sedang dan baik sebesar 3,3\% dan $1,1 \%$. Hasil ini menggambarkan bahwa pengetahuan gizi ibu yang baik belum tentu selaras dengan status gizi normal pada anak. Penelitian di dua kecamatan kota Pekanbaru melaporkan hasil yang sama yaitu tidak ditemukannya hubungan yang positif antara pengetahuan gizi ibu dan status gizi balita ${ }^{20}$. Seorang ibu tidak hanya membutuhkan pengetahuan dalam mengurus anak tetapi juga harus diimbangi dengan faktor lain seperti sikap, kemampuan, serta kepercayaan diri dalam mengurus anak. Selain itu, walaupun ibu mempunyai pengetahuan yang baik tetapi tidak semua ibu mengasuh anaknya sendiri secara langsung. Ibu yang bekerja biasa menitipkan anaknya kepada anggota keluarga lain yang tidak diketahui bagaimana tingkat penegetahuannya terkait gizi. Hasil ini tidak sama dengan penelitian lain yang menunjukkan bahwa pengetahuan gizi ibu mempunyai hubungan yang positif terhadap status gizi dari anak ${ }^{21}$. Pengetahuan gizi menjadi faktor yang penting tetapi tidak selalu pengetahuan yang dimiliki seseorang dapat diterapkan secara langsung.

\section{KESIMPULAN}

Pekerjaan ibu berhubungan dengan status gizi dari balita (BB/TB) usia 6-59 bulan di wilayah kerja dari Puskesmas Kesamben Ngoro, Jombang. Ibu yang tidak bekerja dapat mempunyai waktu lebih untuk mengawasi asupan makan anak. Saran yang diberikan yaitu pihak puskesmas dapat memberi dorongan dan motivasi bagi ibu bekerja terkait pemberian asupan gizi anak yang sesuai kebutuhan. Walaupun bekerja, ibu tetap dapat mengawasi asupan gizi anak melalui pengarahan kepada pengasuh agar anak tetap mendapatkan pengasuhan gizi yang tepat.

\section{ACKNOWLEDGEMENT}

Penulis mengucapkan puji dan syukur kepada Allah Subhanahu Wa Ta'ala atas segala karunia-Nya dan Nikmat-Nya. Penulis juga berterimakasih kepada pihak Puskesmas Kesamben Ngoro Kabupaten Jombang yang telah mengizinkan dan memberi kesempatan pada peneliti untuk melaksanakan penelitian ini.

\section{REFERENS}

1. Fikawati, S., Syafiq, A. \& Veratamala, A. Gizi Anak dan Remaja. (Rajawali Pers, 2017).

2. Kementerian Kesehatan RI. Riset Dasar Kesehatan Tahun 2018. (2019).

3. Kementerian Kesehatan RI. Buku Saku Pemantauan Status Gizi 2017. (2018).

4. UNICEF. The State of World's Children 1998. (Oxford University Press, 1998).

5. Grantham-mcgregor, S. et al. Child development in developing countries 1 Developmental potential in the fi rst 5 years for children in. $\mathbf{3 6 9}$, (2007).

6. Dewey, K. G. The Challenge of Meeting Nutrient Needs of Infants and Young Children during the Period of Complementary Feeding: An Evolutionary Perspective. J. Nutr. 143, 20502054 (2013).

7. Simon, A. K., Hollander, G. A., Mcmichael, A. \& Mcmichael, A. Rspb20143085. Proc. Biol. Sci. 282, 1-12 (2015).

8. Stamenkovic, Z., Djikanovic, B., Laaser, U. \& Bjegovic-mikanovic, V. The role of mother' $s$ education in the nutritional status of children in Serbia. Public Health Nutr. 19, 2734-2742 (2016).

9. Putri, R. F. D. Faktor-Faktor yang Berhubungan dengan Status Gizi Anak Balita di Wilayah Kerja Puskesmas Nanggalo Padang. J. Kesehat. Andalas 4, 254-261 (2015).

10. Rahma, A. C. \& Nadhiroh, S. R. Perbedaan Sosial Ekonomi Dan Pengetahuan Gizi Ibu Balita Gizi 
Kurang Dan Gizi Normal. Media Gizi Indones. 11, 55 (2018).

11. World Health Organization. Nutrition Landscape Information System (NLIS) Country Profile Indicators : Interpretation guide. (2013).

12. Nasikhah, R. \& Margawati, A. Faktor Risiko Kejadian Stunting Pada Balita Usia 24 - 36 Bulan di Kecamatan Semarang Timur. J. Nutr. Coll. 1, 176-184 (2012).

13. Ni'mah, C. \& Lailatul, M. Hubungan Tingkat Pendidikan, Tingkat Pengetahuan dan Pola Asuh Ibu dengan Wasting dan Stunting pada Balita Keluarga Miskin. Media Gizi Indones. 10, 84-90 (2015)

14. Dessie, Z. B., Fentie, M., Abebe, Z., Ayele, T. A. \& Muchie, K. F. Maternal characteristics and nutritional status among $6-59$ months of children in Ethiopia: further analysis of demographic and health survey. BMC Pediatr. 19, 1-10 (2019).

15. Nugraheningtyasari, N. A., Susanti, D. \& Soemyarso, N. A. Correlation between nutritional status of children aged $12-36$ months and mother's working status in Taman , Sidoarjo. Biomol. Heal. Sci. J. 01, 101-104 (2018).

16. Hartono, Widjanarko, B. \& Em, M. S. Hubungan perilaku Keluarga Sadar Gizi ( KADARZI) dan Perilaku Hidup Bersih Sehat ( PBHS ) pada tatanan rumah tangga dengan status gizi balita usia 24-59 bulan. J. Gizi Indones. 5, 88-97 (2017).

17. Rohimah, E., Kustiyah, L. \& Hernawati, N. Pola Konsumsi, Status Kesehatan dan Hubungannya dengan Status Gizi dan Perkembangan Balita. J. Gizi Pangan 10, 93-100 (2015).

18. Eshete, H., Abebe, Y., Loha, E., Gebru, T. \& Tesheme, T. Nutritional Status and Effect of Maternal Employment among Children Aged 6 59 Months in Wolayta Sodo Town, Southern Ethiopia: A Cross-sectional Study. Ethiop. J. Health Sci. 27, 155-162 (2017).

19. Puspasari, N. \& Andriani, M. Hubungan Pengetahuan Ibu tentang Gizi dan Asupan Makan Balita dengan Status Gizi Balita ( BB / U ) Usia 1224 Bulan Association Mother' s Nutrition Knowledge and Toddler's Nutrition Intake with Toddler's Nutritional Status ( WAZ) at the Age 12 -24 M. Amerta Nutr. 1, 369-378 (2017).

20. Saleh, A., Nurachmah, E., Hadju, V., As, S. \& Hamid, S. K. Baby Nutritional Status Improvement Through Mother Empowerment in Baby Care in South Sulawesi Indonesia. Pakistan J. Nutr. 16, 9-15 (2017).

21. Debela, B. L., Demmler, K. M., Rischke, R. \& Qaim, M. Maternal nutrition knowledge and child nutritional outcomes in urban Kenya. Appetite 116, 518-526 (2017). 